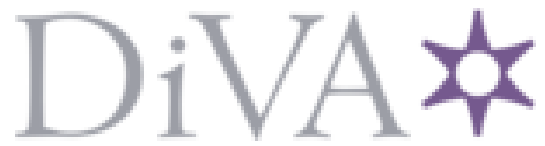

http://www.diva-portal.org

This is the published version of a paper published in .

Citation for the original published paper (version of record):

Shahabi-Ghahfarokhi, S., Rahmati-Abkenar, M., Matson, J G., Karimi, H., Yu, C. et al. (2022)

Removal and potential recovery of dissolved metals from acid sulfate soil drainage by spent coffee-grounds and dissolved organic carbon

Environmental Advances, 8: 100193

https://doi.org/10.1016/j.envadv.2022.100193

Access to the published version may require subscription.

N.B. When citing this work, cite the original published paper.

Permanent link to this version:

http://urn.kb.se/resolve?urn=urn:nbn:se:Inu:diva-110461 


\title{
Removal and potential recovery of dissolved metals from acid sulfate soil drainage by spent coffee-grounds and dissolved organic carbon
}

\author{
Sina Shahabi-Ghahfarokhi ${ }^{\text {a, }}$, Mahboubeh Rahmati-Abkenar ${ }^{a}$, Johan Glenn Matson ${ }^{\text {a }}$ \\ Hadi Karimi $^{\mathrm{b}}$, Changxun Yu ${ }^{\mathrm{a}}$, William Hogland ${ }^{\mathrm{a}}$, Maris Klavinš ${ }^{\mathrm{c}}$, Marcelo Ketzer ${ }^{\mathrm{a}}$ \\ ${ }^{a}$ Faculty of Health and Life Sciences, Department of Biology and Environmental Science, Linnaeus University, kalmar, Sweden \\ ${ }^{\mathrm{b}}$ Department of Geological and Environmental Sciences, Western Michigan University, Kalamazoo, MI, 49008, USA \\ ${ }^{\mathrm{c}}$ Department of Environmental Science, University of Latvia, Rìga LV-1586, Latvia
}

\section{A R T I C L E I N F O}

\section{Keywords:}

Acid sulfate soil

Dissolved organic matter

Metal recovery

Spent coffee-grounds

Remediation, Metal contamination

\begin{abstract}
A B S T R A C T
This study explores the reuse of spent coffee-grounds (SCGs) and the use of dissolved humic acid (DHA) to remediate acid sulfate (AS) soil drainage using adsorption and precipitation experiments, with changing $\mathrm{pH}$, weight/volume, and concentrations (mg/L of dissolved organic carbon). In addition, this study aims to extend the usability of the SCGs, after being reacted with AS soil drainage, by identifying the potential recovery of incinerated SCGs from the ash of the SCGs produced incineration. As compared to DHA, the SCGs had greater efficiency in removing metals, such as $\mathrm{Al}(98 \%)$, Ca (96\%), Co (94\%), Fe (88\%), Mn (100\%), Ni (93\%), and Zn (96\%). However, the removal of Fe was significantly reduced when higher weight/volume of SCGs were introduced. In addition, SCGs could not bind sulfur, while DHA had removed up to 25\% of S from the solution. This suggests the simultaneous use of SCGs and DHA could restrict the formation of problematic Fe(III) secondary compounds (e.g., schwertmannite/akaganeite) which are problematic in some AS soil settings. The results show that $\mathrm{Co}(69 \%)$, Ni (58\%), Mn (60\%), Fe (59\%), Zn (55\%), and $\mathrm{Al}(34 \%)$ had the highest recovery percentage by sequential chemical extraction, respectively. The recovery of metals, as well as the removal of dissolved metals from the drainage water, illustrates the effectiveness of the proposed approach for SCGs reuse.
\end{abstract}

\section{Introduction}

Biosubstances, such as spent coffee-grounds (SCGs), tea, rice hulls (Utomo and Hunter 2006; Kaikake et al. 2007; Kyzas 2012; Nam et al. 2017), and dissolved organic carbon (DOC) such as humic acid (Kluč́ková and Pavlíková 2017) have been used to remove metals from metal-rich solutions. In addition, SCGs have a broad range of applications, such as removal of dyes (Kyzas et al. 2012; Sartape et al. 2017) and metals (Nam et al. 2017) from solutions, and used as sources of energy (Kim and Oh 2021), bio-oil (Yang et al. 2016), biochar (Maree et al. 2020), biocrude production (Yang et al. 2019; Zhang et al. 2021), substitute for coking coal (Maree et al. 2020) and provides adsorption sites for soluble metals and, therefore, be used for water treatment (Utomo and Hunter 2006; Kyzas 2012; Nam et al. 2017). Furthermore, with the worldwide coffee consumption reported to be over 11 billion tons/year (Jagdale et al. 2019), SCGs have great potential for being used as alternative biosorbents for remediation (McNutt and He 2019). In Europe, the most common trend to deal with organic waste, such as
SCGs, is incineration (Kaikake et al. 2007; Šyc et al. 2020) of combustible waste to produce electricity (McNutt and He 2019). In addition, the use of bottom ash from general (mixed) waste for metal recovery has been previously studied (Šyc et al. 2020). Previous studies have used sequential chemical extraction (SCE) experiments to extract metals from incinerated waste, bottom ash (Chaudhary and Banerjee 2007; Xiong et al. 2014; Šyc et al. 2020). With these two properties of SCGs, the usable lifespan of the SCGs is expected to extend by its' reuse to remediate contaminated waterways and finally recover metals from the incineration processes. To the best of our knowledge, the use of SCGs has never been investigated previously for remediating AS soil drainage waters. Also, the potential recovery of metals from SCGs ash has not been evaluated.

Pollutants are introduced into natural and managed environments by direct and indirect human activities (Masindi and Muedi 2018). Potential toxic elements (e.g., toxic metals) can enter water bodies or neighboring environments (lakes, wetlands, and estuaries) from Acid Sulfate (AS) soils drainage systems (Karimian et al. 2017; Shahabi-Ghahfarokhi

\footnotetext{
* Corresponding author.

E-mail address: sina.shahabighahfarokhi@lnu.se (S. Shahabi-Ghahfarokhi).
} 
et al. 2022). AS soils occur mainly along coastlines and consist primarily of marine sulfidic sediments, e.g., deposited during the last sea-level highstand. The main sulfidic components in these materials are iron sulfides (Boman et al. 2008). Under reduced conditions (e.g., below the groundwater table), these materials are harmless (Mattbäck et al. 2022). However, post-glacial uplifts, common in Northern Europe, causes relative sea levels to fall and exposes sulfidic sediments to oxygen into the vadose zone, leading to oxidation of iron sulfides and formation of sulfuric acid (Boman et al. 2008; Shahabi-Ghahfarokhi et al. 2022). In addition, climate change will increase the amplitude of seasonal groundwater table variations in boreal settings and expose more parent material of AS soils into the vadose zone (Jarsjö et al. 2020). All these processes eventually contribute to the formation of AS soils and associated leaching of acidic $(\mathrm{pH}<4)$ and metal-rich solutions from the soils (Gröger et al. 2011; Vithana et al. 2021). In general, the drainage waters from AS soils are rich in many metals, such as cadmium (Cd), zinc ( $\mathrm{Zn})$, nickel (Ni), aluminum (Al), iron (Fe) (Gröger et al. 2011; Shahabi-Ghahfarokhi et al. 2022) and reactive non-metals such as sulfur (S). Aluminum is the most toxic element for the environments under influence of AS soils and has been implicated in extensive fish kills (Powell and Martens 2005; Toivonen et al. 2020). Iron is another metal with environmental threats, because it has suffocating effects for vegetations by producing secondary $\mathrm{Fe}(\mathrm{III})$ precipitates on the surrounding recipient wetland and coastland planes of the AS soil drainage (Sullivan and Bush 2004; Shahabi-Ghahfarokhi et al. 2022). Manganese, Ni, Zn, and Co are trace elements usually reported from AS soil drainage (Åström and Corin 2000) that contribute to diseases if concentrations are over threshold values (Blust 2011; Röllin 2011; Rajput et al. 2018; Genchi et al. 2020). To reduce the risk of contamination and to take advantage of AS soil drainage, removing the metals and $S$ from the solution and eventually recovering would be the most favorable approach for an environmentally friendly (Kaikake et al. 2007) and circular economy (Pires and Martinho 2019) perception.
Therefore, this study investigates the potential of SCGs and DHA for remediating metal-contaminated waterways associated with drained AS soil through adsorption and precipitation reactions. In addition, the results from the adsorption (SCGs) and the precipitation (DHA) experiments are also compared to evaluate the highest uptake of metals from the solution. Furthermore, the interaction of SCGs wastewater with dissolved metals of the drainage is studied. Finally, this study investigates the potential metal recovery after incineration of the metalssorbed SCGs through an SCE scheme.

\section{Methods}

\section{Study site and AS soil drain water collection}

This study uses water samples collected in an artificial drainage system in southern Sweden (Skåne), north of the Kristianstad municipality (Fig. 1). AS soils and metal mobilization (Fe, $\mathrm{Al}, \mathrm{Ni}, \mathrm{Co}, \mathrm{Mn}$ ) in associated artificial drainage systems have been reported in the area (Shahabi-Ghahfarokhi et al. 2022). Over time, the discharge of drained water from AS soils onto the north wetland area has caused environmental degradation by multiple metals (Shahabi-Ghahfarokhi et al. 2022). The AS soils' water is drained and meets in the central drainage system (Fig. 1). On two separate occasions (September 2020 and April 2021), water samples were collected in $10 \mathrm{~L}$ water containers and stored at $4{ }^{\circ} \mathrm{C}$. On-site, the $\mathrm{pH}\left(\mathrm{pH} / \mathrm{mV} /{ }^{\circ} \mathrm{C}\right.$ Meter, Handheld, $\mathrm{pH} 1100 \mathrm{H}$, pHenomenal $($ ) values were immediately measured from the central drainage. The first water sample collected was used for the pre-test (small scale experiments under similar settings of this study), and the second water sample was used for the main experiment of this research. The water samples collected (without treatment) from the drain were directly employed to simulate natural conditions. From both samples, dissolved metal contents were also measured (Section 2.4).

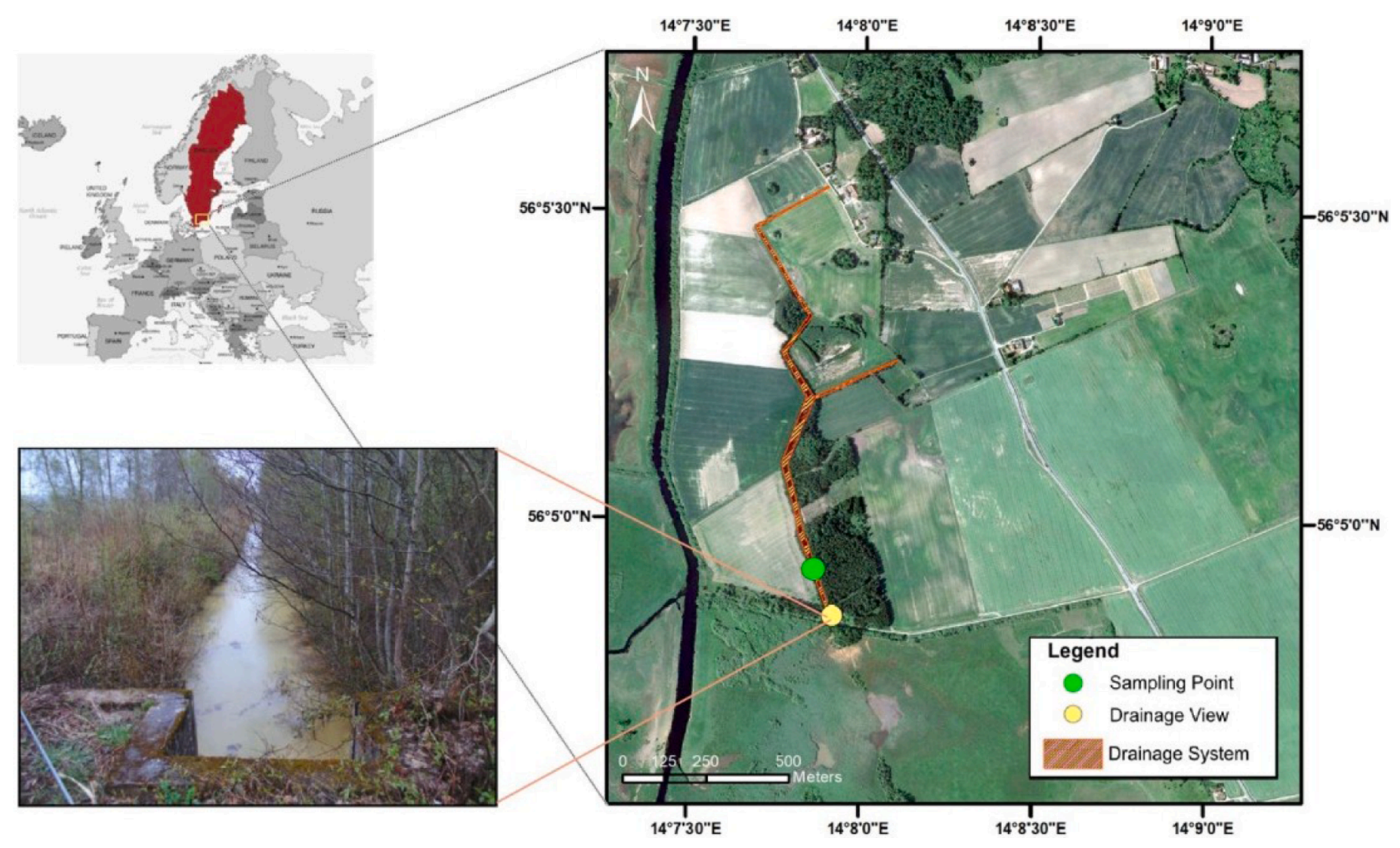

Fig. 1. Illustrating the study site and the view of the drainage system. 


\section{SCGs preparation}

The SCGs were collected from Linnaeus University vending machines (Selecta ${ }^{\circledR}$ coffee vending machines and Pelican Rouge ${ }^{\circledR}$ Amor coffee beans). The wet and fresh SCGs were collected on the same day and treated according to the following steps: The SCGs were pre-treated (Utomo and Hunter 2006) with $0.01 \mathrm{M} \mathrm{NaOH}$ (Sigma-Aldrich) and mixed with a weight to volume ratio (W/V) of 1/10 (dry SCGs to water), and washed with deionized water. The washing was repeated until achieving a non-color supernatant with a TOC $<5 \mathrm{mg} \mathrm{L}^{-1}$. During the washing process DOC (measured with LCK 380 and $381, \mathrm{HACH} \otimes$ kits) and $\mathrm{pH}$ values $\left(\mathrm{pH} / \mathrm{mV} /{ }^{\circ} \mathrm{C}\right.$ Meter, Handheld, $\mathrm{pH} 1100 \mathrm{H}$, pHenomenal $($ ) ) were measured. The SCGs were then washed with Milli-Q water until a pH of $\approx 6$ was achieved (Utomo and Hunter 2006). Finally, the SCGs were air-dried $\left(30^{\circ} \mathrm{C}\right)$ for $24 \mathrm{~h}$, and the dried grains were sieved via a plastic sieve (to avoid metal contamination) into two separated fractions of 500 and $250 \mu \mathrm{m}$ (the 500- and 250- $\mu \mathrm{m}$ fractions consist of $1000-500 \mu \mathrm{m}$ and 500-250 $\mu \mathrm{m}$ fractions, respectively). These separated fractions were used to understand the effect of grain size on the adsorption of elements onto SCGs particles.

\section{Adsorption experiment}

For the experimental adsorption setup, five weights of 0.05, 0.1, 0.5, 1.0 , and $1.5 \mathrm{~g}$ SCGs added to a constant volume of $40 \mathrm{~mL}$ were used to estimate the adsorption capacity of the two different fractions (500 and $250 \mu \mathrm{m}$ ) under altering $\mathrm{pH}$ values of 4.5 and 6.5 (Table 1). After weighing the SCGs into the $50 \mathrm{~mL}$ falcon tubes, the water collected in the field was added to each sample with a dispenser (Poulten \& Graf GmbH FORTUNA $^{\mathrm{TM}}$ OPTIFIX ${ }^{\mathrm{TM}}$ Safety S Dispenser) at a constant volume of 40 $\mathrm{mL}$. The prepared tubes were fixed in racks and shaken (Heavy Duty Shaker, OHAUS ${ }^{\mathrm{TM}}$ ) at $4{ }^{\circ} \mathrm{C}$ (average winter season temperature present in the study region) for $18 \mathrm{~h}$ under dark conditions. The samples were then filtered (cellulose acetate membrane, $0.45 \mu \mathrm{m}$, Whatman) and stored for total metal concentration measurement (Section 2.5). In addition, 6 extra adsorption batch experiments with $500 \mathrm{~mm}$ SCGs under $\mathrm{pH}$ of 6.5 were conducted using the highest W/V ratio (300 gr/ $800 \mathrm{~mL}$, batch 5, Table 1) in 1L bottles (Pyrex ${ }^{\mathrm{TM}}$ Borosilicate Glass Reagent Bottle). Samples with a higher W/V ratio were prepared to have enough material for incineration and the potential metal recovery experiment.

After the adsorption experiments, the contaminated SCGs were merged into 2 groups by mixing the material from 3 of the experiments (after filtration) to further perform the sequential extraction on duplicates. Later, each compiled sample was air-dried and incinerated into ash at $750{ }^{\circ} \mathrm{C}$ (Ghosh et al. 2020) for $5 \mathrm{~h}$ (Heiri et al. 2001).

\section{Precipitation experiment}

For the precipitation experiments, two different reactants were added to the collected water sample under varying $\mathrm{pH}$ of 4.5 and 6.5. The first reactant, dissolved humic acid (DHA), was made by dissolving $2.5 \mathrm{~g}$ of dry humic acid (HUMIN-P 775, Humintech, Germany) in $5 \mathrm{~L}$ of water, leading to $700 \mathrm{mg} \mathrm{L}^{-1}$ DOC (Zhou et al. 2019). For the second reactant, the extract was taken from the 1st step (1st Batch) of washing the SCGs (Table 1), coffee DOC, which leads to a DOC concentration of $1440 \mathrm{mg} / \mathrm{L}$ (Table A1). Based on target DOC concentrations and liquid volumes (Table 1), the addition from DOC stock solutions took place (Table A1). The same $\mathrm{pH}$ values employed in the adsorption experiment were used for the precipitation experiment. A $20-80 \mathrm{mg} \mathrm{L}^{-1}$ DOC range was chosen for the DHA as intervals for the precipitation experiment. The proposed range of DOC final concentrations were chosen for natural processes based on typical DOC leaching values of $40 \mathrm{mg} / \mathrm{L}$ from forest soil (Scheel et al. 2007). To study the lower and higher inputs of DOC, $\pm 40 \mathrm{mg} / \mathrm{L}$ DOC was applied to our center value ( $40 \mathrm{mg} / \mathrm{L}$ ) to study the extent of precipitation in the covering range. Since the aromaticity (Fig A1) of the coffee DOC is almost half of the DHA, it was decided not to use the same volumes added from DHA to keep the volume constant, which leads to double DOC concentrations used (Table 1). All samples were prepared in $50 \mathrm{~mL}$ Falcon tubes, fixed on racks, and shaken at $4{ }^{\circ} \mathrm{C}$ for $18 \mathrm{~h}$. After filtration (cellulose acetate circles membrane, $0.45 \mu \mathrm{m}$, Whatman ${ }^{\circledR}$ ), the DOC was measured (LCK 380 and 381, HACH ${ }^{\circledR}$ ), and the remaining samples were stored for total metal concentration measurement (Section 2.5).

\section{Trace element analysis and sequential chemical extraction}

The filtered liquid supernatant samples were acidified to a $\mathrm{pH}$ below 2 with $1 \% \mathrm{HNO}_{3}$. The samples were then analyzed for concentrations of $\mathrm{Fe}, \mathrm{Al}, \mathrm{Mn}, \mathrm{Ni}, \mathrm{Zn}, \mathrm{Co}, \mathrm{Ca}, \mathrm{Na}$ and S (Table A2-11) with ICP-OES (Thermo Scientific Inc., ICP-OES spectrometry iCAP7000, University of Latvia). The detection limit was 1-10 ppb for $\mathrm{Al}, \mathrm{Ca}$, and $\mathrm{Fe}, 0.1-1 \mathrm{ppb}$ for $\mathrm{Na}$, and $0.1 \mathrm{ppb}$ for all other elements.

To evaluate the potential for metal recovery after incineration, a sequential extraction scheme modified from Tessier and Campbell, (1987) was applied to the incinerated samples (Xiong et al. 2014, See Table 2). Since the material consists of mostly organic matter, the last two steps of the scheme (bound to organic matter and residual fraction) were not included.

- Step 1: Fraction of water-soluble and easily exchangeable compounds. A sample $(1.0000 \pm 0.0050 \mathrm{~g})$ was extracted by $1 \mathrm{M} \mathrm{MgCl}_{2}$ in deionized water in a glass beaker for $1 \mathrm{~h}$ on a mechanical shaker (Tachometer RPM PSU-20, Biosan).

- Step 2: Fraction of weak acid-soluble compounds (e.g., carbonates). Sample left from the 1st step of sequential extraction were carefully

Table 1

The variables ( $\mathrm{pH}$, grain size, and DOC) and loads were used for the adsorption and precipitation experiment.

\begin{tabular}{|c|c|c|c|c|c|c|c|}
\hline \multicolumn{2}{|l|}{ Experiment } & \multicolumn{6}{|c|}{ Variables } \\
\hline \multirow{5}{*}{ Adsorption } & \multirow{2}{*}{ Grain-Size $\mu \mathrm{m}$} & \multirow{2}{*}{$\mathrm{pH}$} & \multicolumn{5}{|c|}{ Weight $(\mathrm{g})$ of SCGs* } \\
\hline & & & Batch1 & Batch2 & Batch3 & Batch4 & Batch5 \\
\hline & 500 & 4.5 & 0.05 & 0.1 & 0.5 & 1 & 1.5 \\
\hline & 500 & 6.5 & 0.05 & 0.1 & 0.5 & 1 & 1.5 \\
\hline & 250 & & & & & & \\
\hline \multirow[t]{4}{*}{ Precipitation } & DOC & $\mathrm{pH}$ & DOC mg & & & & \\
\hline & & & Batch1 & Batch2 & Batch3 & Batch4 & Batch5 \\
\hline & Coffee1st extract & 4.5 & 40 & 60 & 80 & 120 & 160 \\
\hline & & 6.5 & & & & & \\
\hline
\end{tabular}

*Each weight of coffee is reacted with $40 \mathrm{~mL}$ of liquid sample **From each stock, DHA, and coffee extract, volumes were added to reach $40 \mathrm{~mL}$ and the target DOC value (Appendix 1). The terms used are: spent coffee-grounds (SCGs), dissolved organic carbon (DOC), and dissolved humic acid (DHA). 
Table 2

The sequential extraction scheme used for this study.

\begin{tabular}{|c|c|c|c|c|c|c|}
\hline \multirow[b]{2}{*}{ Fraction } & \multirow[b]{2}{*}{ Fraction Name } & \multirow[b]{2}{*}{ Agent } & \multicolumn{2}{|l|}{ Conditions } & \multicolumn{2}{|c|}{ Changes made by Xiong et al., (2019) } \\
\hline & & & Mixing time (hour) & $\mathrm{V}(\mathrm{mL})$ & $\mathrm{V}(\mathrm{mL})$ & Time (hour) \\
\hline 1 & Water soluble and Exchangeable & $1 \mathrm{M} \mathrm{MgCl}_{2}$ & 1 & 8 & 18 & 2 \\
\hline 2 & Bound to carbonates & $1 \mathrm{M} \mathrm{NaOAc}$ & Until necessary & 8 & 15 & 5 \\
\hline 3 & Bound to $\mathrm{Fe}$ and Mn oxides & $0.04 \mathrm{M} \mathrm{NH}_{2} \mathrm{OH}_{-} \mathrm{HCl}$ in $25 \% \mathrm{HOAc}$ & Until necessary & 20 & 30 & 6 \\
\hline
\end{tabular}

collected into a glass beaker and extracted with $40 \mathrm{~mL}$ of $1 \mathrm{M}$ $\mathrm{NaOOCCH}_{3}$ for $16 \mathrm{~h}$ on a mechanical shaker (Tachometer RPM PSU20, Biosan).

- Step 3: Fraction of reducible compounds. Sample left from the 2nd step of sequential extraction were collected into a glass beaker and extracted with $20 \mathrm{~mL}$ of $0.5 \mathrm{M} \mathrm{NH}_{2} \mathrm{OH} \times \mathrm{HCl}$ for $16 \mathrm{~h}$ on a mechanical shaker.

After each step, double filtration of extracts using a paper filter and a membrane filter $(0.45 \mu \mathrm{m}$, Simplepure $)$ were done; the extracts were put into polypropylene tubes and diluted with deionized water to $50 \mathrm{~mL}$ and acidified with $0.7 \mathrm{M} \mathrm{HNO}_{3}$. Each analytical solution was made in triplicate and, at each step, blank samples were prepared in the same manner. All obtained extracts were stored until analyses in a cool place $\left(+4{ }^{\circ} \mathrm{C}\right)$. The quality of the analytical measurements was ensured by the analysis of certified reference material IAEA-336 Lichen containing reference values on wide spectra of major and minor elements.

\section{Results and discussion}

\section{AS soil drain water $p H$ and metal concentration}

Records show the different $\mathrm{pH}$ values (4.5 and 6.5) and element concentrations measured from the drain system (Table 3 ). From the measured $\mathrm{pH}$, the two values were included as the minimum and maximum $\mathrm{pH}$ variables in the adsorption and precipitation experiments. In case of the low $\mathrm{pH}$ event, during the water sampling in 2020, the water was pumped out of the drain system, allowing more drainage and potentially exposing the parent material to oxidation and lowering the $\mathrm{pH}$. This is supported by the fact that the concentrations of metals, in particular, $\mathrm{Al}$ and $\mathrm{Fe}$, were higher during the low $\mathrm{pH}$ events. The low $\mathrm{pH}$ and higher soluble metal values correlate with the AS soils being drained. The same feature was also seen in other AS soil settings, where higher concentrations of elements were observed in the drain waters during active drainage and low pH (Dang et al., 2018). Comparing the available threshold values of the Swedish EPA (Swedish EPA 2000), Zn and $\mathrm{Ni}$ on different occasions show concentrations above EPA threshold values. For $\mathrm{Zn}$, in low and high $\mathrm{pH}$ values in drainage water, concentrations are high and very high (class IV and V, Table 3), respectively, when compared to Swedish EPA threshold values (Swedish EPA 2000). In addition, under low and high $\mathrm{pH}$ events, Ni shows low and very high concentrations (class II and V, Table 3), respectively, when compared to threshold values of the Swedish EPA (Swedish EPA 2000). Class II is classified as a slight risk for biological effects (Swedish EPA 2000), whereas classes 4 and 5 are classified as increasing risks for biological effects. The most significant are the effects of class 5 metal contaminations, where even short-term exposure affects organisms (Swedish EPA 2000).

\section{Monitoring of SCGs washing steps and $\mathrm{NaOH}$ treatment}

Two parameters, including $\mathrm{pH}$ and DOC and visually observed color changes, were used to control the SCGs washing procedure (Fig. 2). The supernatant in each washing step (batch 1-13) shows a decreasing DOC concentration, increasing $\mathrm{pH}$, and changing color from brown to transparent (Fig. 2). Previous research (Utomo and Hunter 2006) has used visual recognition (transparent watercolor) to judge the final step of the SCGs washes. However, as illustrated in Fig. 2, from washing step number 10, it will be challenging to identify the final wash even though the solutions still contain high levels of DOC $\left(<100 \mathrm{mg} \mathrm{L}^{-1}\right)$. This study shows that TOC and $\mathrm{pH}$ are more appropriate parameters for identifying the final washing step. Also, ensuring close to zero DOC concentrations coming from the SCGs will reduce the spontaneous formations of precipitates, metal-DOC complexes, and aid in distinguishing between the adsorption and precipitation processes. The $\mathrm{pH}$ also could indicate the solution has reached a stable condition when the washing $\mathrm{NaOH}$ solution $(\mathrm{pH} 11.8)$ shows the extracted DOC has reached its minimum (Fig. 2).

From the washing steps, it is evident that Na has been adsorbed onto the washed SCGs (Table A3-10). The increasing Na concentration released into solution after the $18 \mathrm{~h}$ adsorption experiment (Fig. 3) might indicate a weak bond of Na from the pre-treatment washing step onto the SCGs. Also, confirming that even with the after wash with distilled water, the $\mathrm{Na}$ is still adsorbed. In addition, it is evident that with different volumes of SCGs added, the Na introduced into solution is increased. This increasing concentration of Na could affect the adsorption processes by altering the ionic strength, which is discussed in the next chapter (chapter 3.3). Because of the known Na toxicity effects in aquatic systems and water quality (Corsi et al. 2010), the increase of $\mathrm{Na}$ by SCGs addition shall be considered for the application in the field.

\section{Adsorption}

Aluminum, Ca, Co, and Mn show an overall higher adsorption (91$98 \%, 95-96 \%, 92-94 \%$, and $99-100 \%$, respectively) onto SCGs in the $\mathrm{pH}$ $=6.5$ than in $\mathrm{pH}=4.5$ with no relation to grain sizes (Fig. 4). For $\mathrm{Ca}$, the

Table 3

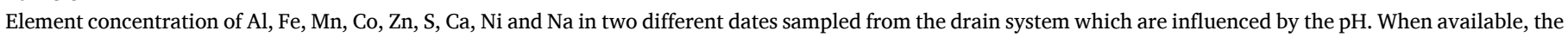

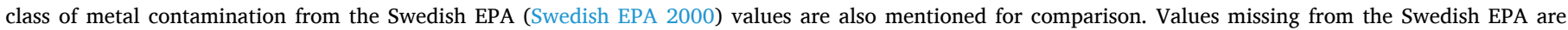
mentioned as no data (n.d).

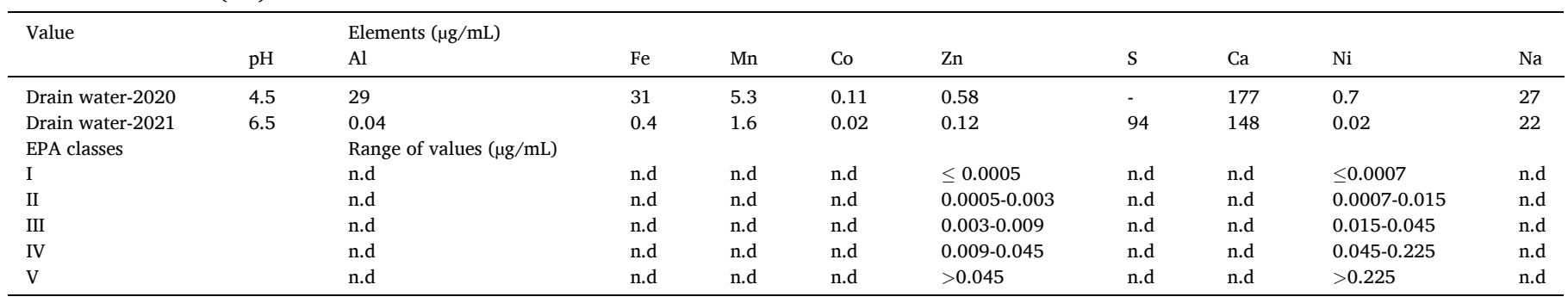




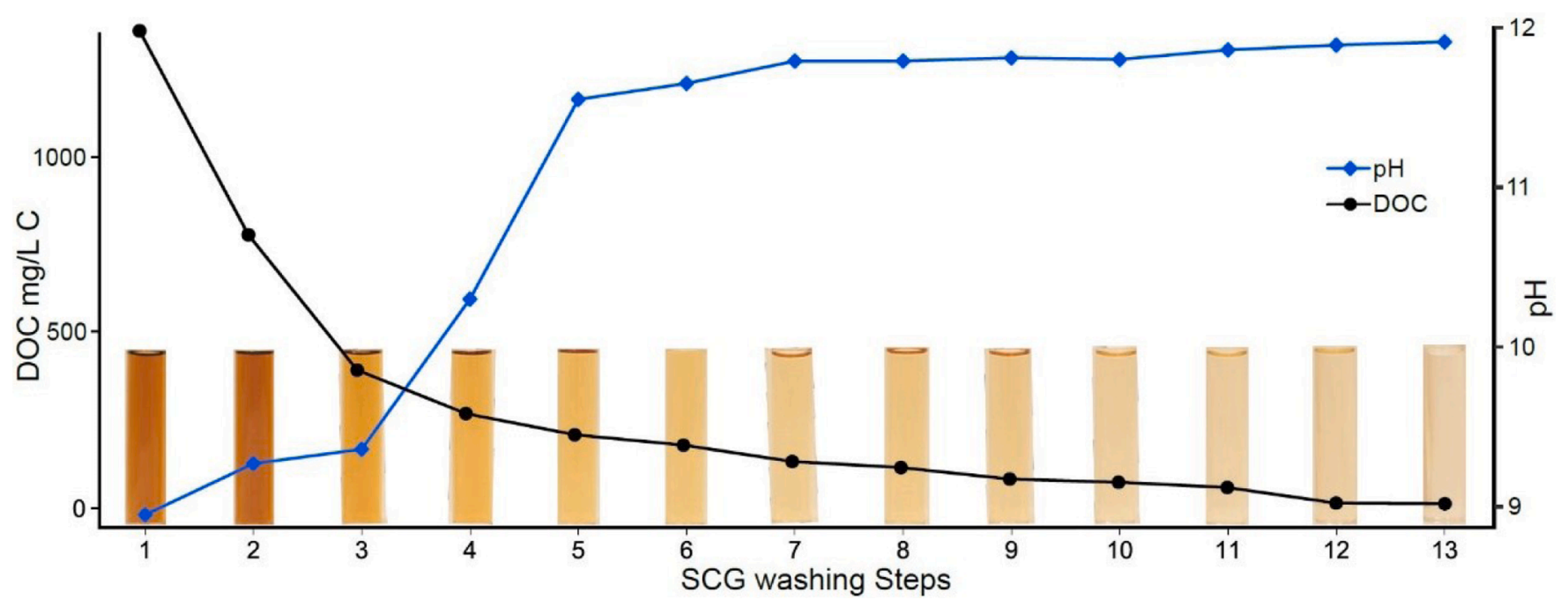

Fig. 2. Inverse relation of $\mathrm{pH}$ and dissolved organic carbon (DOC) is 13 steps of washed the spent coffee-grounds (SCGs) water and the color change of each sequence.
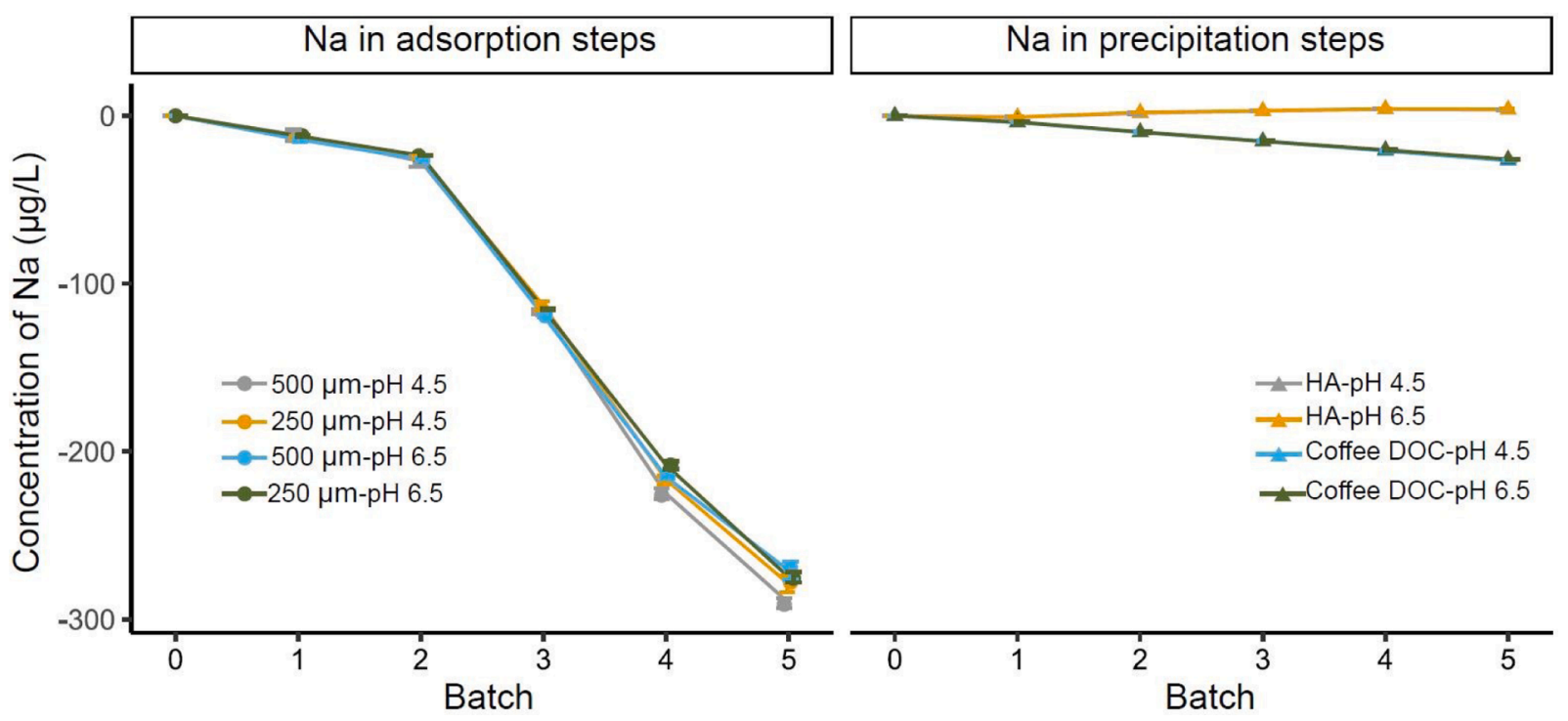

Fig. 3. Sodium ( $\mathrm{Na}$ ) concentrations were released into solution over the adsorption (left graph) and precipitation experiment (right graph). For batch information refer to Table 1. The dissolved humic acid (DHA) and coffee DOC are used in the precipitation experiment.

adsorption equilibrium was not reached even though the uptake is close to $100 \%$ (Fig. 4), indicating the affinity of dissolved calcium interacting with SCGs. Comparing Al to Fe (75-88\% adsorbed), the latter shows a slightly higher adsorption capacity and removal rates with smaller grain sizes. For $\mathrm{Ni}$ and $\mathrm{Zn}$, the lower $\mathrm{pH}$ values have increased the adsorption capacity ( $93 \%$ and $95-96 \%$, respectively) of SCGs when compared to $\mathrm{pH}$ $6.5(81-82 \%$ and $74 \%$, respectively), without the grain size affecting the percentage of adsorbed $\mathrm{Co}, \mathrm{Ni}$, and $\mathrm{Zn}$. For most elements, with an increasing weight of SCGs $(>0.05 / 40 \mathrm{~W} / \mathrm{V})$, the competition over adsorption seems to be smaller, and hence less adsorbed elements were observed (Fig. 4). This decreasing trend of adsorption with addition of SCGs is also evident in normalized values (mass of adsorbed metal normalized by mass of SCG, Fig A2 and Table A12). The most substantial decrease of adsorption is for Fe (Fig. 4 and A2). SCGs adsorbs close to $90 \%$ of Fe in the solution of batch 1 and almost $30-45 \%$ in the last batch 13 (1.5/40 W/V). In addition, the SCGs does not show any affinity for S; therefore, the results were not included in the adsorption experiment. Multiple mechanisms could explain the decreasing adsorption of soluble Fe with higher SCGs addition. The adsorption times used in this study are higher than in previous SCGs adsorption studies (Lavecchia et al. 2016; Nam et al. 2017; Sukhbaatar et al. 2021), which could cause desorption. However, Kyzas et al. (2012) reports the adsorption of soluble metals onto SCGs under experimental adsorption times up to $24 \mathrm{~h}$, which do not indicate desorption of soluble metals from the SCGs. In addition, with increasing adsorbers, the aggregation of bio-adsorbers is probable, thus reducing the adsorption sites (Sartape et al. 2017; Mashkoor et al. 2018). That mechanism is also unlikely because our samples were agitated during the experiment. Finally, the soluble $\mathrm{Na}$ released into solution with increasing addition of SCGs (Fig. 3), increases the ionic strength of the solution and might reduce the $\mathrm{pH}$, which causes desorption or reduce the adsorption of soluble metals onto SCGs. Although the $\mathrm{pH}$ and ionic strength of solutions during and after the experiment were not measured, this mechanism is likely to decrease the adsorption of soluble elements with increasing SCGs.

The results show that the tested grain sizes don't affect the adsorption capacity, while the $\mathrm{pH}$ of the solution plays a more critical role in the uptake of these metals. The methods to brew, bean type, and the growing conditions of coffee beans are variables that can change the 


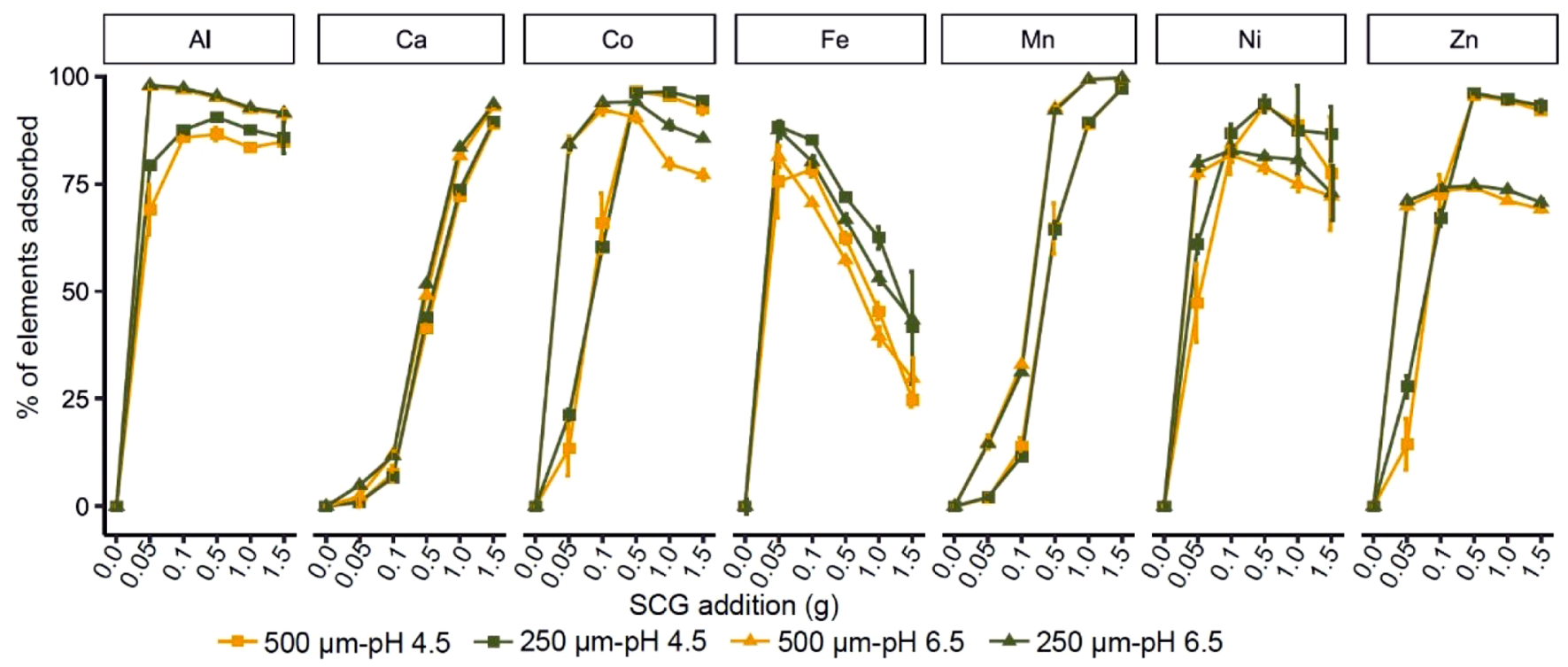

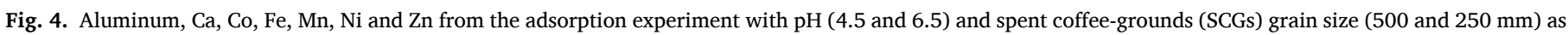
variables. For batch information please refer to Table 1.

adsorption properties of SCGs (Blinová et al. 2017; McNutt and He 2019). For $\mathrm{Al}, \mathrm{Co}, \mathrm{Ni}$, and $\mathrm{Zn}$ (Fig. 4) at higher $\mathrm{pH}$ values, the adsorption slightly decreases even with increasing the amount of SCGs added to the solution. This has also been observed previously by Utomo \& Hunter (2006) for $\mathrm{Zn}$, in which $60 \%$ (from $1 \mathrm{~mL} \mathrm{~L}^{-1}$ and $\mathrm{pH} 5$ ) is adsorbed by SCGs. Chromium also had previously shown affinity ( $45 \mathrm{mg} / \mathrm{g}$ ) to SCGs and weak adsorption when solutions were acidic, $\mathrm{pH}<6$ (Kyzas 2012). Calcium might not be problematic, however, in acidic settings with large quantities of $\mathrm{CaCO}_{3}$ additions to increase the $\mathrm{pH}$ of soils (Aström 1998), the dissolved Ca can cause a color change and can precipitate to cause white surfaces (Lydersen et al. 2002). With the effects of Ca known (Åström 1998), removing this metal from AS soil drainage waters could improve local environmental statuses by removing the dissolved Ca.

\section{Precipitation}

The precipitation results show that DHA, with higher aromatic content (Fig. A1), has higher metal removal than coffee DOC (Fig. 5a). The role of $\mathrm{pH}$ is more prominent for $\mathrm{Al}, \mathrm{Ca}, \mathrm{Co}, \mathrm{Mn}$, and $\mathrm{S}$. For $\mathrm{Al}$, like adsorption, the precipitation reaches the highest value at the $\mathrm{pH}=6.5$, for both DHA and coffee DOC additions (87-92 \% and 70-93\%, respectively). Overall, the coffee DOC additions were only effective for Al, and all other elements have smaller precipitation values when compared to DHA additions. However, in $\mathrm{pH}=6.5$, the coffee DOC shows slightly higher precipitation rates when compared to a solution with $\mathrm{pH}=4.5$. Calcium, Co, and Mn show a higher precipitation for DHA under the $\mathrm{pH}$ $=6.5(4-28 \%, 20-70 \%$, and 7-43\%, respectively), and slightly lower (2$24 \%, 3-62 \%$, and $4-33 \%$, respectively) for $\mathrm{pH}=4.5$. When looking at $\mathrm{Fe}$ and $\mathrm{Ni}$ removed percentages by precipitation, it is evident that with fewer DOC concentrations (Fig. 5a), higher precipitation occurs at $\mathrm{pH}=$ 4.5 rather than at $\mathrm{pH}=6.5$. The Fe and Ni removed by precipitation is $28-79 \%$ and $8-56 \%$ at $\mathrm{pH} 4.5$ and $36-74 \%$ and $30-50 \%$ at $\mathrm{pH}=6.5$, respectively. In the case of $\mathrm{Zn}$, the addition of DHA or coffee DOC has almost the same effect (Figs. $5 \mathrm{a}$ and $\mathrm{b}$ ), with lower $\mathrm{pH}$ giving higher precipitation percentage (9-72\% and 5-65\%, respectively) at lower DOC concentrations (batch 1-3) when compared to $\mathrm{pH}=6.5$ (26-61\% and 30 $48 \%$, respectively). Overall, for most elements, this shows the effectiveness of DHA under different changing $\mathrm{pH}$ environments with slightly less precipitation under acidic conditions.

Sulfur precipitation and adsorption results show a higher affinity for DOC in forming complexes in precipitates rather than SCGs adsorption
(Fig. 4-5). Under the two pH conditions, DHA and coffee DOC have very similar abilities in precipitating $\mathrm{S}$ complexes (up to $25 \%$ ). The formation of $\mathrm{Fe} / \mathrm{Al}$ (hydroxide)-DOC complexes during the addition of DHA or coffee DOC could provide adsorption sites for sulfate (Tamrat et al. 2019, Sadeghalvad et al. 2021), which are dominant in AS soil drainage (Green et al. 2007) and counted as total S measurements in solution. In addition, the removal of $\mathrm{S}$ and $\mathrm{Fe}$, restricts the formation of problematic Fe species such as schwertmannite (Fitzpatrick et al. 2017) and akaganeite (Shahabi-Ghahfarokhi et al. 2022) in acidic settings. Schwertmannite is reported to form a suffocating media as it precipitates on plants in adjacent AS soil drainage areas (Fitzpatrick et al. 2017). Coffee DOC is not recommended since its environmental-related issues, related to high nutrient and DOC load that could lead to the formation of anoxic zones in aquatic environments, having previously been reported by Campos et al. (2021). In acidic settings, with available sulfate and Fe, the formation of schwertmannite is highly probable (Fitzpatrick et al. 2017). These iron sulfate species in Mediterranean (Fitzpatrick et al. 2017), tropical (Johnston et al. 2010; Keene et al. 2011; Johnston et al. 2016), and subtropical (Ahern et al. 2004; Claff et al. 2010) regions have caused severe vegetation degradation by forming schwertmannite and/or akaganeite, two poorly crystalline Secondary Fe(III) phases (Shahabi-Ghahfarokhi et al. 2022). Therefore, by using SCGs and HA, the formation of these problematic secondary iron species are potentially restricted by limiting the Fe and sulfate to form schwertmannite/akaganeite, often seen in sulfuric rich, acidic settings (Burton et al. 2021; Shahabi-Ghahfarokhi et al. 2022). However, the effects of simultaneous addition of SCGs and DHA should be further studied.

\section{SCE of metals in ash and the overall approach}

From the SCE ( $\sum 3$ steps), it could be seen that Co, Ni, Mn, Fe, Zn, and $\mathrm{Al}$ present the highest percentage of recovery, respectively (Table 4). However, the overall highest extractions from the $\sum \mathrm{SCE}$ belongs to $\mathrm{Zn}$, $\mathrm{Al}, \mathrm{Co}, \mathrm{Fe}, \mathrm{Mn}$, and Ni. Looking at the separate steps of the contaminated SCE results for $\mathrm{Al}, \mathrm{Co}, \mathrm{Fe}$, and $\mathrm{Mn}$, the highest percentage of SEC recovery is obtained from the Fe and Mn oxides phases (Fig. 6).

In addition, $\mathrm{Ni}$ and $\mathrm{Zn}$ also show an increased percentage in the SCE fraction bound to carbonates (Fig. 6).

An essential part of solid waste management is incineration (Šyc et al. 2020). The obtained ash also contains high Al, Fe, Mn, Ni, and Zn (Silva et al. 2019; Šyc et al. 2020) concentrations. Zinc, compared to Ni, 

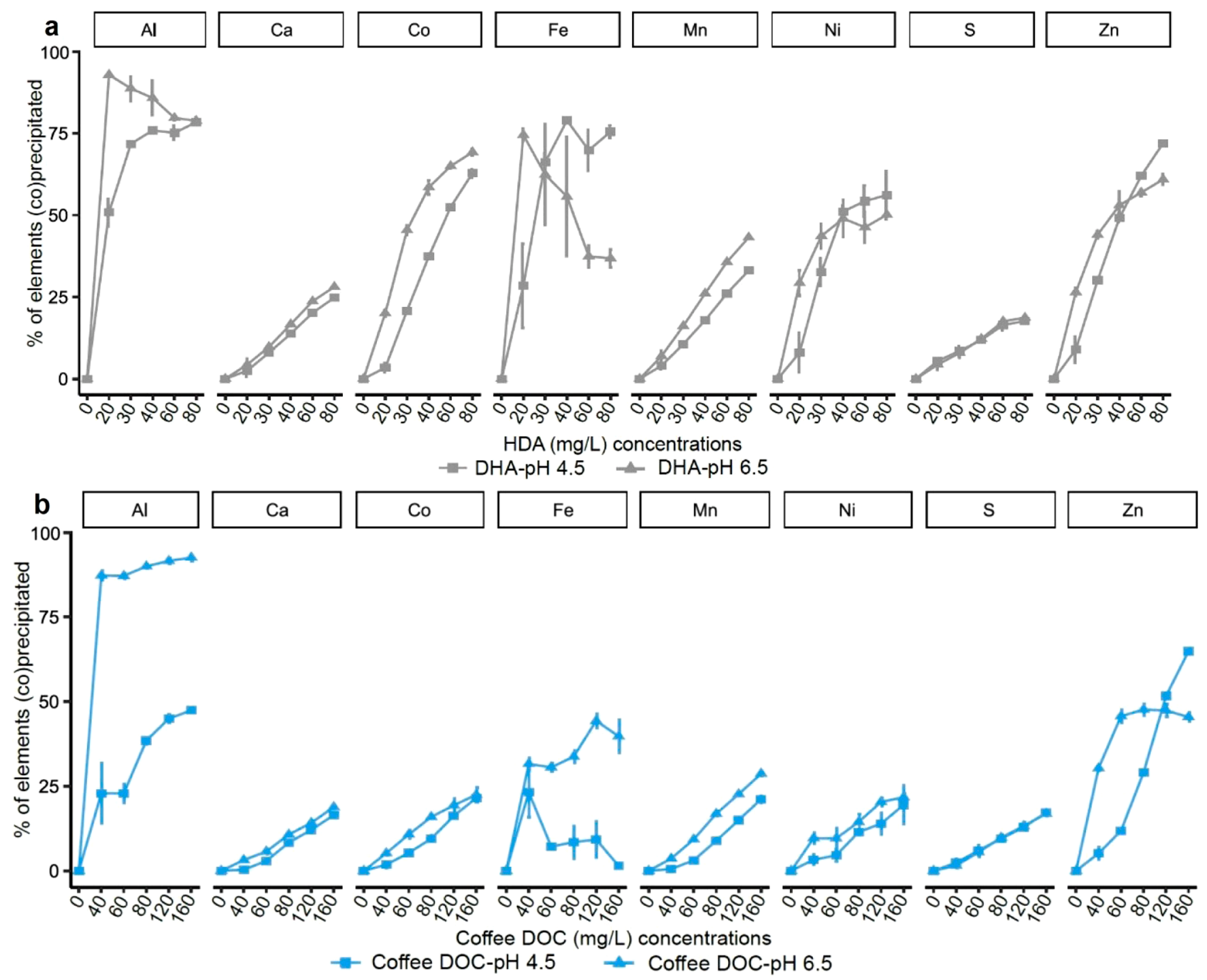

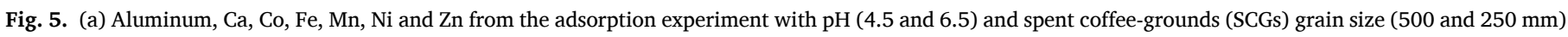

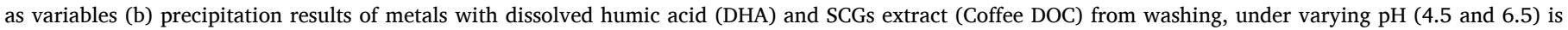
illustrated.

Table 4

Percentage and standard deviation of recovered elements from ash spent coffeegrounds (SCGs). The standard deviation (SD) for $\mathrm{Zn}$ is not provided since a duplicate sample provided no value.

\begin{tabular}{lllllll}
\hline Variables & $\begin{array}{l}\text { Element } \\
\mathrm{Al}\end{array}$ & $\mathrm{Co}$ & $\mathrm{Fe}$ & $\mathrm{Mn}$ & $\mathrm{Ni}$ & $\mathrm{Zn}$ \\
\hline Coffee Recovery \% & 34 & 69 & 59 & 60 & 68 & 55 \\
$\mathrm{SD}$ & 2.16 & 13 & 0.214 & 28 & 5.59 & - \\
\hline
\end{tabular}

has also shown to have the highest percentage of the $\sum$ SCE, and both were found in easily accessible fractions (Eukowski, 2022). For Mn (Bruder-Hubscher et al., 2002), Co (Nurmesniemi et al., 2008), Al, and Fe (Haberl and Schuster, 2019), previous research have also indicated the low potential of these elements to be removed from bottom ash and mainly present in the reducible phases (Bruder-Hubscher et al. 2002; Nurmesniemi et al. 2008). In this study, the proposed strategy for reusing SCGs in AS soil drainage waters or acid mine tailings is presented in Fig. 7. The initial usage of SCGs, for remediation of metal contaminated waters, is followed by the recovery of metals from the incinerated waste (SCGs), which can further extend its lifespan (Fig. 7). In addition, other valuable compounds such as rare earth elements (REEs) (Mondal et al. 2019) should also be studied, and their potential recovery from SCGs used in AS soil drainage could be evaluated. This is due to the nature of AS soil settings that contain up to several $\mathrm{mg} \mathrm{kg}^{-1}$ of REEs in their recipients (Astrom et al. 2020).

\section{Conclusion}

The element uptake (Al (98\%), Ca (96\%), Co (94\%), Fe (88\%), Mn (100\%), Ni (93\%), and Zn (96\%)) for SCGs has higher percentage compared to the precipitated with DHA (Al (92\%), Ca (28\%), Co (70\%), Fe (79\%), Mn (43\%), Ni (56\%), and Zn (72\%)). However, the spent coffee-grounds did not show any affinity towards $S$ adsorption. In contrast, DHA and coffee DOC forms complex with $S$ and removes up to $25 \%$ of the soluble $S$. The coffee DOC extract also shows affinity towards $\mathrm{Al}$ (93\% adsorption). However, with the known environmental impact of SCGs wastewater, the usage of this extract is not recommended. Therefore, combining SCGs and dissolved DHA in AS soil drainage settings is recommended to restrict the formation of Fe(III) secondary minerals such as schwertmannite and/or akaganeite, which can cause environmental degradation. In addition, for SCGs, the effect of grain size on adsorption of studied elements is negligible. However, $\mathrm{pH}$ has 

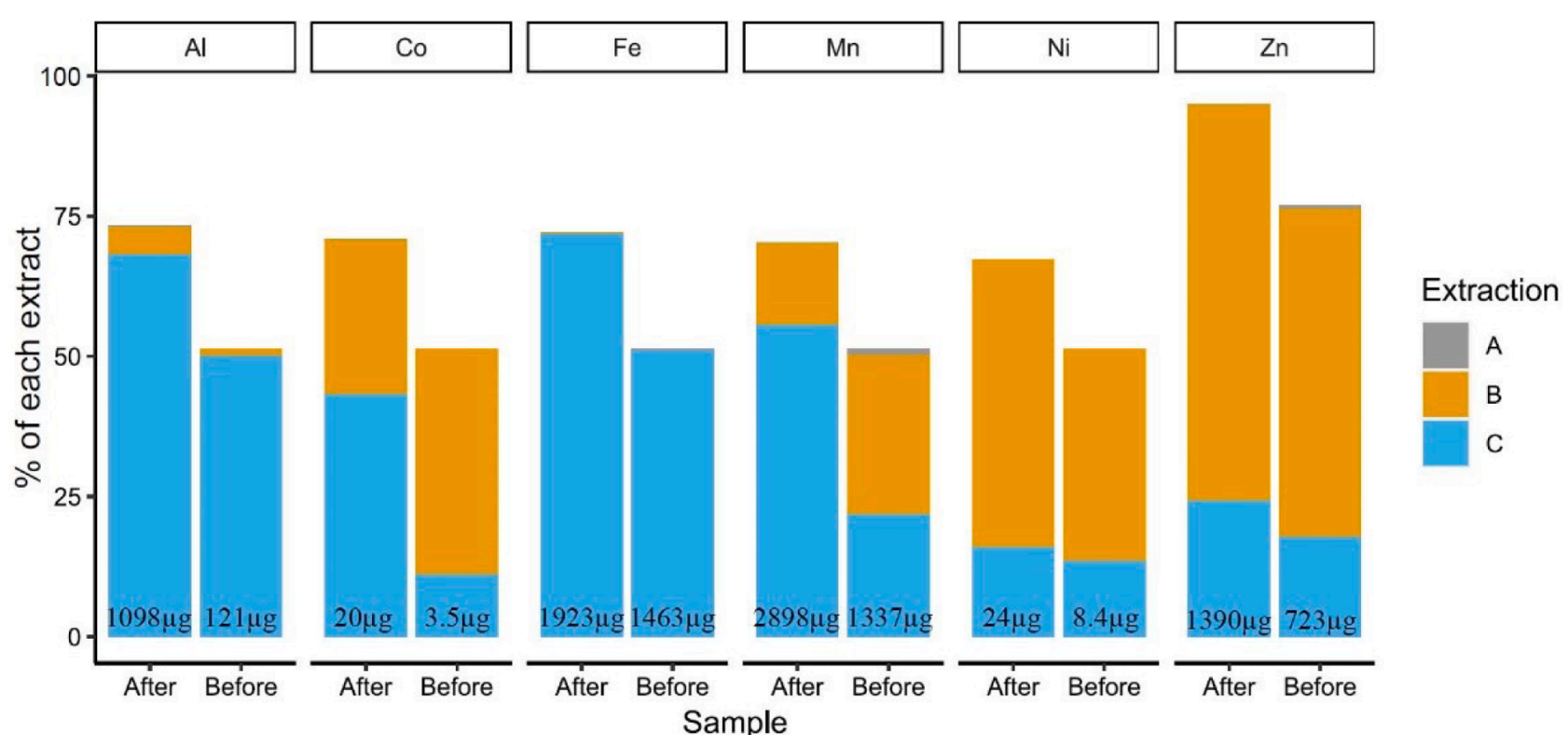

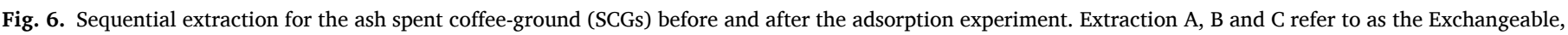

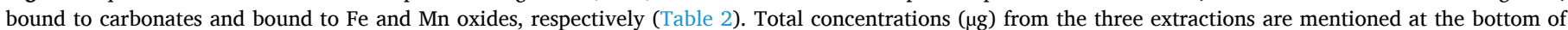
each sample.

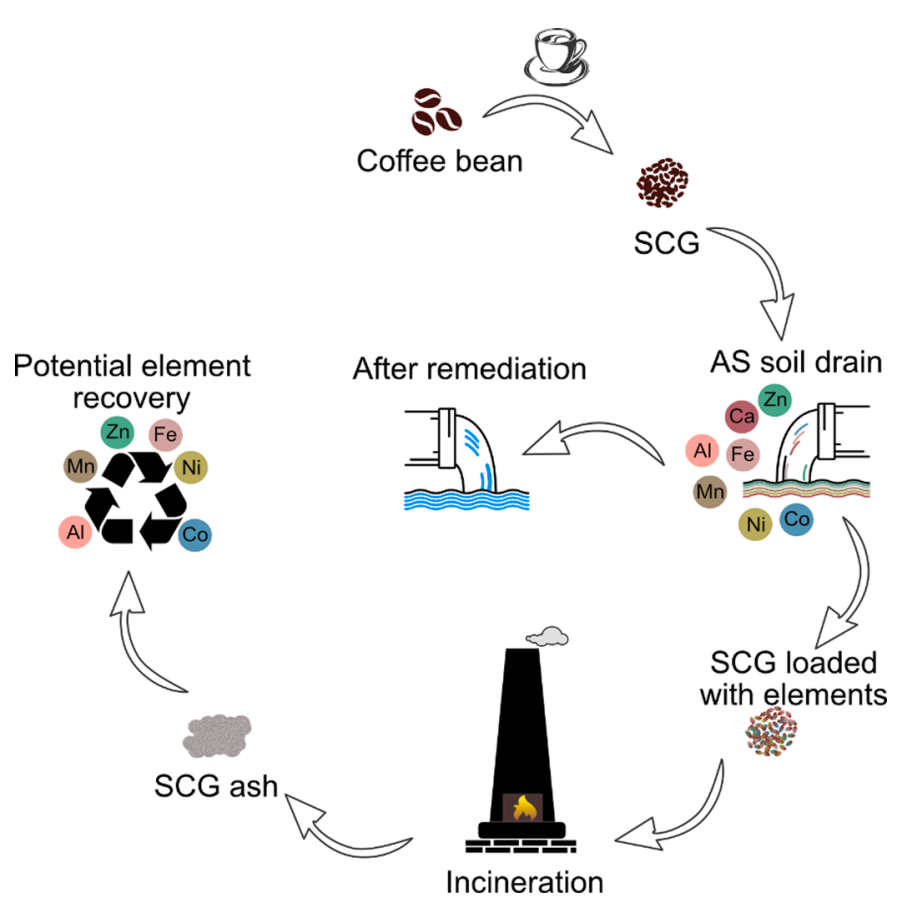

Fig. 7. The overall approach chosen for the re-use of the spent coffee-grounds (SCGs) to remediate acid sulfate (AS) soil drainage water and the potential recovery of $\mathrm{Al}, \mathrm{Mn}, \mathrm{Zn}, \mathrm{Fe}, \mathrm{Ni}$, and Co from the loaded SCGs.

opposite effects on the removal of different metals, that is, $\mathrm{Al}$, Co and $\mathrm{Ca}$ had higher adsorption efficiency in the high $\mathrm{pH}(\mathrm{pH}=6.5)$ experiment, whereas, $\mathrm{Zn}$ and $\mathrm{Ni}$ were removed more efficiently in the low $\mathrm{pH}$ $(\mathrm{pH}=4.5)$ experiment.

The washing steps of the SCGs could affect the obtained results in single and combined methods for element adsorption, because the DOC could affect the adsorption by precipitation with the DOC of the SCGs. The Na released into the solution from treated SCGs could be additionally decreased by washing the SCGs further with Milli-Q water. However, this washing technique is recommended to separate the adsorption from precipitation in experiments. In the real-world scenarios, additional washing steps SCGs will increase the processing costs of SCGs and produce additional wastewater. Therefore, other costeffective techniques for treating SCGs should be studied/tested in the future.

The lifespan of the loaded/contaminated SCGs can be extended by potential element recovery from the incinerated ash product. The results show that Co (69\%), Ni (58\%), Mn (60\%), Fe (59\%), Zn (55\%), and Al (34\%) had the highest recovery percentage by sequential chemical extraction, respectively. Therefore, the reuse of SCGs for remediation and their application for metals recovery after incineration in municipal waste is beneficial. Furthermore, with the impact of climate change on the groundwater recharges in the boreal landscapes, the leached metals from the drained AS soil could be a potential source for metal recovery by using substances such as the SCGs. In addition to the application of SCGs for the remediation of AS soil drainage waters and metal recovery from the remaining SCGs, other similar environments such as acid mine drainage might also be suitable environments for such treatments. This is due to the low $\mathrm{pH}$ and consequently the high metal concentrations of the acid mine drainage.

\section{CRediT authorship contribution statement}

Sina Shahabi-Ghahfarokhi: Conceptualization, Methodology, Validation, Software, Formal analysis, Writing - original draft, Visualization. Mahboubeh Rahmati-Abkenar: Methodology, Validation, Investigation, Writing - review \& editing. Johan Glenn Matson: Investigation, Writing - review \& editing. Hadi Karimi: Software, Writing - review \& editing, Visualization. Changxun Yu: Validation, Writing - review \& editing. William Hogland: Resources, Writing review \& editing. Maris Klavinš: Resources, Writing - review \& editing. Marcelo Ketzer: Resources, Writing - review \& editing, Supervision.

\section{Declaration of Competing Interests}

The authors declare that they have no known competing financial interests or personal relationships that could have appeared to influence the work reported in this paper. 


\section{Acknowledgments}

We thank the Kristianstad municipality and the University of Kristianstad (HKR) for their close collaboration. In addition, we thank Linnaeus University (LNU) for the Ph.D. scholarship to Sina ShahabiGhahfarokhi and Anders Johnson from LNU for checking the English grammar of this research article. Also, we thank Thérese Lindquist for her lab assistance.

\section{Funding}

In this research article, no funding sources were used.

\section{Supplementary materials}

Supplementary material associated with this article can be found, in the online version, at doi:10.1016/j.envadv.2022.100193.

\section{References}

Ahern, CR, McElnea, AE, Sullivan, LA, 2004. Queensland, department of natural resources mines and energy. Acid Sulfate Soils-Laboratory Methods Guidelines. Dept. of Natural Resources, Mines \& Energy, Indooroopilly, Qld.

Åström, M, 1998. Mobility of Al, P and alkali and alkaline earth metals in acid sulphate soils in Finland. Sci. Total Environ. 215, 19-30. https://doi.org/10.1016/S00489697(98)00006-0.

Åström, M, Corin, N, 2000. Abundance, sources and speciation of trace elements in humus-rich streams affected by acid sulphate soils. Aquat. Geochem. 6, 367-383. https://doi.org/10.1023/A:1009658231768.

Astrom, M, Yu, C, Virtasalo, J, Österholm, P, Peltola, P, Burton, E, Hogmalm, J, Ojala, A, 2020. Extensive accumulation of rare earth elements in estuarine sediments affected by leaching of acid sulfate soils. Boreal Environ. Res. 25, 105-120.

Blinová L, Sirotiak M, Pastierova A, Soldán M (2017) Review-utilization of waste from coffee production. Research Papers Faculty of Materials Science and Technology Slovak University of Technology 25. 10.1515/rput-2017-0011.

Blust, R, 2011. 6 - Cobalt. In: Wood, CM, Farrell, AP, Brauner, CJ (Eds.), Fish Physiology. Academic Press, pp. 291-326.

Boman, A, Åström, M, Fröjdö, S, 2008. Sulfur dynamics in boreal acid sulfate soils rich in metastable iron sulfide-The role of artificial drainage. Chem. Geol. 255, 68-77. https://doi.org/10.1016/j.chemgeo.2008.06.006.

Bruder-Hubscher, V, Lagarde, F, Leroy, MJF, Coughanowr, C, Enguehard, F, 2002. Application of a sequential extraction procedure to study the release of elements from municipal solid waste incineration bottom ash. Analytica Chimica Acta 451 (2), 285-295. https://doi.org/10.1016/S0003-2670(01)01403-9.

Burton, ED, Karimian, N, Johnston, SG, Schoepfer, VA, Choppala, G, Lamb, D, 2021. Arsenic-imposed effects on schwertmannite and jarosite formation in acid mine drainage and coupled impacts on arsenic mobility. ACS Earth Space Chem. 5, 1418-1435. https://doi.org/10.1021/acsearthspacechem.1c00047.

Campos, RC, Pinto, VRA, Melo, LF, Rocha, SJSS da, Coimbra, JS, 2021. New sustainable perspectives for "Coffee Wastewater" and other by-products- A critical review. Future Foods 4, 100058. https://doi.org/10.1016/j.fufo.2021.100058.

Chaudhary, S, Banerjee, DK, 2007. Speciation of some heavy metals in coal fly ash. Chem. Speciat. Bioavailab. 19, 95-102. https://doi.org/10.3184/ $095422907 X 236100$.

Claff, SR, Sullivan, LA, Burton, ED, Bush, RT, 2010. A sequential extraction procedure for acid sulfate soils-Partitioning of iron. Geoderma 155, 224-230. https://doi.org/ 10.1016/j.geoderma.2009.12.002.

Corsi, SR, Graczyk, DJ, Geis, SW, Booth, NL, Richards, KD, 2010. A fresh look at road salt-Aquatic toxicity and water-quality impacts on local, regional, and national scales. Environ. Sci. Technol. 44, 7376-7382. https://doi.org/10.1021/es101333u.

Dang, T, Marschner, P, Fitzpatrick, R, Mosley, LM, 2018. Assessment of the binding of protons, $\mathrm{Al}$ and $\mathrm{Fe}$ to biochar at different $\mathrm{ph}$ values and soluble metal concentrations. Water 10, 55. https://doi.org/10.3390/w10010055.

Fitzpatrick, RW, Mosley, LM, Raven, MD, Shand, P, 2017. Schwertmannite formation and properties in acidic drain environments following exposure and oxidation of acid sulfate soils in irrigation areas during extreme drought. Geoderma 308, 235-251. https://doi.org/10.1016/j.geoderma.2017.08.012.

Genchi, G, Carocci, A, Lauria, G, Sinicropi, MS, Catalano, A, 2020. Nickel-Human health and environmental toxicology. Int. J. Environ. Res. Public Health 17. https://doi. org/10.3390/ijerph17030679.

Ghosh, P, Sengupta, S, Singh, L, Sahay, A, 2020. Chapter 8 - Life cycle assessment of waste-to-bioenergy processes-A review. In: Singh, L, Yousuf, A, Mahapatra, DM (Eds.), Bioreactors. Elsevier, pp. 105-122.

Green, R, Waite, TD, Melville, MD, 2007. Treatment of acid sulfate soil drainage by direct application of alkaline reagents. Water Air Soil Pollut. 178, 59-68. https://doi.org/ 10.1007/s11270-006-9131-0.

Gröger, J, Proske, U, Hanebuth, TJJ, Hamer, K, 2011. Cycling of trace metals and rare earth elements (REE) in acid sulfate soils in the Plain of Reeds, Vietnam. Chem. Geol. 288, 162-177. https://doi.org/10.1016/j.chemgeo.2011.07.018.
Haberl, J, Schuster, M, 2019. Solubility of elements in waste incineration fly ash and bottom ash under various leaching conditions studied by a sequential extraction procedure. Waste Manag 15 (87), 268-278. https://doi.org/10.1016/j. wasman.2019.02.001.

Heiri, O, Lotter, AF, Lemcke, G, 2001. Loss on ignition as a method for estimating organic and carbonate content in sediments-Reproducibility and comparability of results. J. Paleolimnol. 25, 101-110. https://doi.org/10.1023/A:1008119611481.

Jagdale, P, Ziegler, D, Rovere, M, Tulliani, JM, Tagliaferro, A, 2019. Waste coffee ground biochar-A material for humidity sensors. Sensors 19, 801. https://doi.org/10.3390/ s19040801.

Jarsjö, J, Andersson-Sköld, Y, Fröberg, M, Pietroń, J, Borgström, R, Löv, Å, Kleja, DB, 2020. Projecting impacts of climate change on metal mobilization at contaminated sites-Controls by the groundwater level. Sci. Total Environ. 712, $135560 \mathrm{https}$ ///doi. org/10.1016/j.scitotenv.2019.135560.

Johnston, SG, Burton, ED, Bush, RT, Keene, AF, Sullivan, LA, Smith, D, McElnea, AE, Ahern, CR, Powell, B, 2010. Abundance and fractionation of Al, Fe and trace metals following tidal inundation of a tropical acid sulfate soil. Appl. Geochem. 25, 323-335. https://doi.org/10.1016/j.apgeochem.2009.11.015.

Johnston, SG, Morgan, B, Burton, ED, 2016. Legacy impacts of acid sulfate soil runoff on mangrove sediments-Reactive iron accumulation, altered sulfur cycling and trace metal enrichment. Chem. Geol. 427, 43-53. https://doi.org/10.1016/j. chemgeo.2016.02.013.

Kaikake, K, Hoaki, K, Sunada, H, Dhakal, RP, Baba, Y, 2007. Removal characteristics of metal ions using degreased coffee beans-Adsorption equilibrium of cadmium(II). Bioresour. Technol. 98, 2787-2791. https://doi.org/10.1016/j. biortech.2006.02.040.

Karimian, N, Johnston, SG, Burton, ED, 2017. Effect of cyclic redox oscillations on water quality in freshwater acid sulfate soil wetlands. Sci. Total Environ. 581-582, 314-327. https://doi.org/10.1016/j.scitotenv.2016.12.131.

Keene, AF, Johnston, SG, Bush, RT, Sullivan, LA, Burton, ED, McElnea, AE, Ahern, CR, Powell, B, 2011. Effects of hyper-enriched reactive Fe on sulfidisation in a tidally inundated acid sulfate soil wetland. Biogeochemistry 103, 263-279. https://doi.org/ 10.1007/s10533-010-9461-2.

Kim, H-J, Oh, S-C, 2021. Hydrothermal Carbonization of Spent Coffee Grounds. Appl. Sci. 11, 6542. https://doi.org/10.3390/app11146542.

Klučáková M, Pavlíková M (2017) Lignitic humic acids as environmentally-friendly adsorbent for heavy metals. In: J. Chem.. https://www.hindawi.com/journals/jch em/2017/7169019/. Accessed 21 Dec 2020.

Kyzas, GZ, 2012. Commercial coffee wastes as materials for adsorption of heavy metals from aqueous solutions. Materials (Basel) 5, 1826-1840. https://doi.org/10.3390/ ma5101826.

Kyzas, GZ, Lazaridis, NK, ACh, Mitropoulos, 2012. Removal of dyes from aqueous solutions with untreated coffee residues as potential low-cost adsorbents-Equilibrium, reuse and thermodynamic approach. Chem. Eng. J. 189-190, 148-159. https://doi.org/10.1016/j.cej.2012.02.045.

Lavecchia, R, Medici, F, Patterer, MS, Zuorro, A, 2016. Lead removal from water by adsorption on spent coffee grounds. Chem. Eng. Trans. 47, 295-300. https://doi. org/10.3303/CET1647050.

Łukowski, A, 2022. Fractions of Zinc, Chromium and Cobalt in Municipal Solid Waste Incineration Bottom Ash. Journal of Ecological Engineering 23 (3), 12-16. https:// doi.org/10.12911/22998993/145765.

Lydersen, E, Löfgren, S, Arnesen, RT, 2002. Metals in scandinavian surface waters-Effects of acidification, liming, and potential reacidification. Crit. Rev. Environ. Sci. Technol. 32, 73-295. https://doi.org/10.1080/10643380290813453.

Maree, Z, Strydom, CA, Bunt, JR, 2020. Chemical and physical characterization of spent coffee ground biochar treated by a wet oxidation method for the production of a coke substitute. Waste Manag. (Oxford) 113, 422-429. https://doi.org/10.1016/j. wasman.2020.06.025.

Mashkoor, F, Nasar, A, Inamuddin, Asiri AM, 2018. Exploring the reusability of synthetically contaminated wastewater containing crystal violet dye using tectona grandis sawdust as a very low-cost adsorbent. Sci. Rep. 8, 8314. https://doi.org/ 10.1038/s41598-018-26655-3.

Masindi V, Muedi KL (2018) Environmental contamination by heavy metals. Heavy metals. 10.5772/intechopen.76082.

Mattbäck, S, Boman, A, Sandfält, A, Österholm, P, 2022. Leaching of acid generating materials and elements from coarse- and fine-grained acid sulfate soil materials. J. Geochem. Explor. 232, 106880 https://doi.org/10.1016/j.gexplo.2021.106880.

McNutt, J, He, Q, Sophia, 2019. Spent coffee grounds-A review on current utilization. J. Ind. Eng. Chem. 71, 78-88. https://doi.org/10.1016/j.jiec.2018.11.054.

Mondal, S, Ghar, A, Satpati, AK, Sinharoy, P, Singh, DK, Sharma, JN, Sreenivas, T, Kain, V, 2019. Recovery of rare earth elements from coal fly ash using TEHDGA impregnated resin. Hydrometallurgy 185, 93-101. https://doi.org/10.1016/j. hydromet.2019.02.005.

Nam, G, Kim, M-S, Lee, N, Choi, Y-H, Ahn, JW, 2017. An environmentally benign approach for as (V) absorption from wastewater using untreated coffee grounds-Preliminary results. Water 9, 867. https://doi.org/10.3390/w9110867.

Nurmesniemi, H, Pöykiö, R, Kuokkanen, T, Rämö, J, 2008. Chemical sequential extraction of heavy metals and sulphur in bottom ash and in fly ash from a pulp and paper mill complex. Waste Manag Res 26 (4), 389-399. https://doi.org/10.1177/ $0734242 X 07079051$.

Pires, A, Martinho, G, 2019. Waste hierarchy index for circular economy in waste management. Waste Manag. (Oxford) 95, 298-305. https://doi.org/10.1016/j. wasman.2019.06.014.

Powell, B, Martens, M, 2005. A review of acid sulfate soil impacts, actions and policies that impact on water quality in Great Barrier Reef catchments, including a case study 
on remediation at East Trinity. Mar. Pollut. Bull. 51, 149-164. https://doi.org/ 10.1016/j.marpolbul.2004.10.047.

Rajput, VD, Minkina, TM, Behal, A, Sushkova, SN, Mandzhieva, S, Singh, R, Gorovtsov, A, Tsitsuashvili, VS, Purvis, WO, Ghazaryan, KA, Movsesyan, HS, 2018 Effects of zinc-oxide nanoparticles on soil, plants, animals and soil organisms-A review. Environ. Nanotechnol. Monit. Manag. 9, 76-84. https://doi.org/10.1016/j. enmm.2017.12.006.

Röllin, H, 2011. Manganese-Environmental pollution and health effects 617-629.

Sadeghalvad, B, Khorshidi, N, Azadmehr, A, Sillanpää, M, 2021. Sorption, mechanism, and behavior of sulfate on various adsorbents-A critical review. Chemosphere 263, 128064. https://doi.org/10.1016/j.chemosphere.2020.128064.

Sartape, AS, Mandhare, AM, Jadhav, VV, Raut, PD, Anuse, MA, Kolekar, SS, 2017. Removal of malachite green dye from aqueous solution with adsorption technique using Limonia acidissima (wood apple) shell as low cost adsorbent. Arabian J. Chem. 10, S3229-S3238. https://doi.org/10.1016/j.arabjc.2013.12.019.

Scheel, T, Dörfler, C, Kalbitz, K, 2007. Precipitation of dissolved organic matter by aluminum stabilizes carbon in acidic forest soils. Soil Sci. Soc. Am. J. 71, 64-74. https://doi.org/10.2136/sssaj2006.0111.

Shahabi-Ghahfarokhi, S, Åström, M, Yu, C, Lindquisit, T, Djerf, H, Kalbitz, K, Ketzer, M, 2022. Extensive dispersion of metals from hemiboreal acid sulfate soil into adjacent drain and wetland. Appl. Geochem. 136, 105170 https://doi.org/10.1016/j. apgeochem.2021.105170.

Silva, RV, de Brito, J, Lynn, CJ, Dhir, RK, 2019. Environmental impacts of the use of bottom ashes from municipal solid waste incineration-A review. Resour. Conserv. Recycl. 140, 23-35. https://doi.org/10.1016/j.resconrec.2018.09.011.

Sukhbaatar, B, Yoo, B, Lim, J-H, 2021. Metal-free high-adsorption-capacity adsorbent derived from spent coffee grounds for methylene blue. RSC Adv. 11, 5118-5127. https://doi.org/10.1039/D0RA09550H.

Sullivan, LA, Bush, RT, 2004. Iron precipitate accumulations associated with waterways in drained coastal acid sulfate landscapes of eastern Australia. Mar. Freshwater Res. 55, 727-736. https://doi.org/10.1071/MF04072.

Swedish EPA, 2000. Environmental Quality Criteria for Lakes and Watercourses. Swedish Environmental Protection Agency (Naturvårdsverket), Stockholm.

Šyc, M, Simon, FG, Hykš, J, Braga, R, Biganzoli, L, Costa, G, Funari, V, Grosso, M, 2020. Metal recovery from incineration bottom ash-State-of-the-art and recent developments. J. Hazard. Mater. 393, 122433 https://doi.org/10.1016/j. jhazmat.2020.122433.
Tamrat, WZ, Rose, J, Grauby, O, Doelsch, E, Levard, C, Chaurand, P, Basile-Doelsch, I, 2019. Soil organo-mineral associations formed by co-precipitation of $\mathrm{Fe}, \mathrm{Si}$ and $\mathrm{Al}$ in presence of organic ligands. Geochim. Cosmochim. Acta 260, 15-28. https://doi. org/10.1016/j.gca.2019.05.043.

Tessier, A, Campbell, P.G.C, 1987. Partitioning of trace metals in sediments: Relationships with bioavailability. In: Thomas R.L., Evans R., Hamilton A.L., Munawar M., Reynoldson T.B., Sadar M.H. (eds) Ecological Effects of In Situ Sediment Contaminants. Developments in Hydrobiology. Springer, Dordrecht. https://link.springer.com/chapter/10.1007/978-94-009-4053-6_5\#citeas.

Toivonen, J, Hudd, R, Nystrand, M, Österholm, P, 2020. Climatic effects on water quality in areas with acid sulfate soils with commensurable consequences on the reproduction of burbot (Lota lota L.). Environ. Geochem. Health 42, 3141-3156. https://doi.org/10.1007/s10653-020-00550-1.

Utomo, HD, Hunter, KA, 2006. Adsorption of heavy metals by exhausted coffee grounds as a potential treatment method for waste waters. e-J. Surf. Sci. Nanotechnol. 4, 504-506. https://doi.org/10.1380/ejssnt.2006.504.

Vithana, CL, Ulapane, PAK, Chandrajith, R, Sullivan, LA, Bundschuh, J, Toppler, N, Ward, NJ, Senaratne, A, 2021. Acid sulfate soils on the west coast of Sri Lanka-A review. Geoderma Reg. 25, e00382. https://doi.org/10.1016/j.geodrs.2021.e00382.

Xiong, Y, Zhu, F, Zhao, L, Jiang, H, Zhang, Z, 2014. Heavy metal speciation in various types of fly ash from municipal solid waste incinerator. J. Mater. Cycles Waste Manag. 16, 608-615. https://doi.org/10.1007/s10163-014-0274-6.

Yang, J, Sophia, He, Q, Yang, L, 2019. A review on hydrothermal co-liquefaction of biomass. Appl. Energy 250, 926-945. https://doi.org/10.1016/j. apenergy.2019.05.033.

Yang, L, Nazari, L, Yuan, Z, Corscadden, K, Xu, C, Charles, He, Q, Sophia, 2016. Hydrothermal liquefaction of spent coffee grounds in water medium for bio-oil production. Biomass Bioenergy 86, 191-198. https://doi.org/10.1016/j. biombioe.2016.02.005.

Zhang, S, Yang, J, Wang, S, Rupasinghe, HPV, He, Q, Sophia, 2021. Experimental exploration of processes for deriving multiple products from spent coffee grounds. Food Bioprod. Process. 128, 21-29. https://doi.org/10.1016/j.fbp.2021.04.012.

Zhou, J, Laumann, S, Heimovaara, TJ, 2019. Applying aluminum-organic matter precipitates to reduce soil permeability in-situ-A field and modeling study. Sci. Total Environ. 662, 99-109. https://doi.org/10.1016/j.scitotenv.2019.01.109. 